Special issue of the 3rd International Conference on Computational and Experimental Science and Engineering (ICCESEN 2016)

\title{
Effect of Phase Change Materials on Time Lag, Decrement Factor and Heat-Saving
}

\begin{abstract}
F. Bilgin AND M. ARICI*
Kocaeli University, Engineering Faculty, Mechanical Engineering Department, 41380 Kocaeli, Turkey

In this study, the effect of phase change materials on the time lag, decrement factor and heat-saving is examined numerically. The calculations are conducted for four different cities located at different climatic zones in Turkey, considering both summer and winter conditions, in order to explore the potential heating and cooling energy savings by employing phase change materials. A solar-air temperature, which is a function of time and solar radiation, was taken into consideration as external boundary condition for each city. The results of the present study show that employment of phase change materials in walls of the buildings has a pronounced effect on the time lag and decrement factor. It is concluded that a significant amount of heating energy can be saved and thermal comfort can be enhanced considerably by incorporating phase change materials into external walls. However, a proper phase change material must be selected, considering different climatic conditions.
\end{abstract}

DOI: 10.12693/APhysPolA.132.1102

PACS/topics: 44.05. +e, 88.10.cn, 88.40.-j

\section{Nomenclature}

$k$ thermal conductivity [W/mK]

$h$ heat transfer coefficient $\left[\mathrm{W} / \mathrm{m}^{2} \mathrm{~K}\right]$

$C_{p}$ specific heat $[\mathrm{J} / \mathrm{kg} \mathrm{K}]$

$L_{\mathrm{H}}$ latent heat $[\mathrm{J} / \mathrm{kg}]$

$T$ temperature [K]

$R$ total solar radiation $\left[\mathrm{W} / \mathrm{m}^{2}\right]$

$t$ time $[\mathrm{s}]$

$P$ period [s]

$x$ axial coordinate $[\mathrm{m}]$

$L$ total wall length $[\mathrm{m}]$

$f$ liquid fraction

Greek symbols

$\rho$ density $\left[\mathrm{kg} / \mathrm{m}^{3}\right]$

$\alpha$ thermal diffusivity $\left[\mathrm{m}^{2} / \mathrm{s}\right]$

$\alpha_{G}$ absorptivity

$\varepsilon$ emissivity

$\sigma \quad$ Stefan-Boltzmann constant $\left[\mathrm{W} / \mathrm{m}^{2} \mathrm{~K}^{4}\right]$

Subscripts

in inside

out outside

$m$ melting

d day-long

sa solar-air

\section{Introduction}

Nowadays, fossil fuels are commonly used and are increasingly depleted. Therefore, there has been a growing interest in alternative energy sources, such as solar

\footnotetext{
*corresponding author; e-mail: muslumarici@gmail.com
}

energy [1-4] and in energy saving [5, 6]. Recently, incorporation of phase change materials (PCM) into building structures has become a fashion method to reduce heating and cooling energy consumption (hence to save energy), due to their high thermal mass [7].

Athienitis et al. [8] studied experimentally and numerically the application of PCM in building envelope components. They have shown that maximum room temperature can be increased by about $4{ }^{\circ} \mathrm{C}$ during the daytime and heating load at night can be reduced significantly by utilization of PCM. Huang et al. [9] studied theoretically the effect of different PCM materials, for selected ambient conditions of temperature and insolation in UK, on the thermal performance. PCM with melting point of $28^{\circ} \mathrm{C}$ was determined as a contributing factor to the interior ambient temperature, when tested in June and January. Diaconu and Cruceru [10] studied numerically the potential of a wall system consisting of two wallboards, impregnated with different PCMs for cooling and heating energy savings in continental temperate climates. They reported that the proposed wall system contributes to annual energy savings and reduces the peak value of the cooling and heating loads. Halford and Boehm [11] investigated numerically the peak cooling load shifting by using the encapsulated PCM. A one-dimensional model was developed with sinusoidal temperature boundary conditions. As a result of their study, difference between conditions of utilization of PCM and conditions without PCM was determined. Asan [12] examined the impact of twenty-six different building materials and eight different thicknesses of each material on the time lag (TL) and decrement factor (DF) and reported that both, the type of material and the thickness of material, have a significant effect on the TL and DF. Sun et al. [13] studied experimentally and numerically the influence of the outside temperature of a building on the TL and DF. Twelve different types of envelopes were tested in a wind tunnel. Crank-Nicolson finite difference model was used for the 
numerical study. They reported that TL of temperature peaks does not always equal the TL of temperature crests and TL and DF change when the mean outside temperature continuously rises or falls. Lai and Hokoi [14] studied experimentally the thermal performance of an aluminium honeycomb wallboard, containing microencapsulated PCM and concluded that the latent heat can be used to increase the time lag and to lower surface temperatures.

In this study, the effect of two different PCM on the TL, DF and heat-saving is examined numerically. Besides, in order to investigate the effect of the climatic conditions on the performance of PCM wall, computations are performed for four cities in Turkey, which are located in different climatic zones, considering both heating and cooling conditions.

\section{Materials and methods}

The sandwiched external wall, examined in this study, consists of four layers. These are, from inner side to outer side, $20 \mathrm{~mm}$ of mortar, $40 \mathrm{~mm}$ of PCM, $200 \mathrm{~mm}$ of concrete and $20 \mathrm{~mm}$ of mortar. The schematic geometry of the wall is shown in Fig. 1.

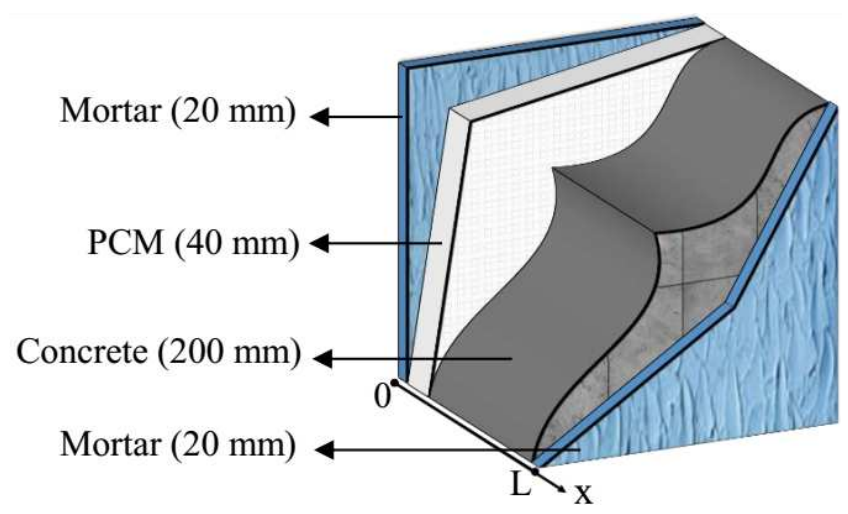

Fig. 1. The schematic of the external wall.

Two different PCM are examined in the study. PCM1 is employed for heating conditions while PCM2 is employed for cooling conditions. The thermo-physical properties of the wall materials are given in Table I.

TABLE I

Thermo-physical properties of the materials $[15,16]$.

\begin{tabular}{c|c|c|c|c|c|c}
\hline \hline Name & Phase & $\begin{array}{c}\rho \\
{\left[\mathrm{kg} / \mathrm{m}^{3}\right]}\end{array}$ & $\begin{array}{c}k \\
{[\mathrm{~W} / \mathrm{m} \mathrm{K}]}\end{array}$ & $\begin{array}{c}C_{p} \\
{[\mathrm{~J} / \mathrm{kg} \mathrm{K}]}\end{array}$ & $\begin{array}{c}T_{m} \\
{\left[{ }^{\circ} \mathrm{C}\right]}\end{array}$ & $\begin{array}{c}L_{\mathrm{H}} \\
{[\mathrm{J} / \mathrm{kg}]}\end{array}$ \\
\hline Concrete & Solid & 2300 & 1.40 & 880 & - & - \\
Mortar & Solid & 1860 & 0.72 & 840 & - & - \\
PCM1 & Solid & 880 & 0.2 & 2000 & 8 & 175000 \\
& Liquid & 770 & & & & \\
PCM2 & Solid & 880 & 0.2 & 2000 & 23.5 & 190000
\end{tabular}

It is assumed heat transfer through the wall is one dimensional, thermo-physical properties do not vary with temperature and convective currents of the melted PCM are negligible. Under these assumptions, the governing equation can be expressed as:

$$
\frac{\partial T}{\partial t}=\alpha \frac{\partial^{2} T}{\partial x^{2}}
$$

where $\alpha$ is the thermal diffusivity of each material, which is calculated as $k / \rho C_{p}$. Equation 1 is valid for fully solid or liquid case of PCM. However, in order to take account, the phase change process (melting or solidification) of PCM layer an additional term must be included, as in Eq. (2) [17].

$$
\frac{\partial T}{\partial t}=\alpha \frac{\partial^{2} T}{\partial x^{2}}-\frac{L_{H}}{C_{p}} \frac{\partial f}{\partial t},
$$

where $L_{H}$ is the latent heat of fusion of PCM material and $f$ is the liquid fraction in the PCM layer. Convection boundary condition is applied on both sides of the wall. Boundary conditions at the inner and outer surfaces are given by Eq. (3) and Eq. (4), respectively.

$$
\begin{aligned}
& \left.k \frac{\partial T}{\partial x}\right|_{x=0}=h_{\mathrm{in}}\left[T_{x=0}(t)-T_{\mathrm{in}}\right], \\
& -\left.k \frac{\partial T}{\partial x}\right|_{x=L}=h_{\text {out }}\left[T_{x=L}(t)-T_{\mathrm{sa}}(t)\right],
\end{aligned}
$$

where $h_{\text {in }}$ and $h_{\text {out }}$ represent heat transfer coefficients on the inner and outer surfaces of the wall and are taken to be $9 \mathrm{~W} / \mathrm{m}^{2} \mathrm{~K}$ and $22 \mathrm{~W} / \mathrm{m}^{2} \mathrm{~K}$, respectively [18]. $T_{\text {in }}$ is the indoor temperature, which is set to $18^{\circ} \mathrm{C}$. $T_{\mathrm{sa}}$ is solar-air temperature that combines the effect of solar radiation and outdoor temperature and is calculated using Eq. (5) [19].

$$
T_{\mathrm{sa}}(t)=T_{\mathrm{d}}(t)+\frac{\alpha_{G} R}{h_{\text {out }}}-\frac{\varepsilon \sigma\left(T_{\mathrm{d}}^{4}(t)-T_{\mathrm{sky}}^{4}\right)}{h_{\text {out }}},
$$

where $T_{\text {sky }}$ is thy sky temperature, which is assumed to be $12{ }^{\circ} \mathrm{C}$ for summer and $-43^{\circ} \mathrm{C}$ for winter conditions [20]. $R$ is the total radiation from the horizontal plane [21]. $\alpha_{G}$ is absorptivity, assumed to be $0.6, \varepsilon$ is emissivity, assumed to be 0.4 [15] and $\sigma$ is the Stefan-Boltzmann constant $\left(5.67 \times 10^{-8} \mathrm{~W} / \mathrm{m}^{2} \mathrm{~K}^{4}\right)$. The variation of outdoor temperature in any given day can be represented by Eq. (6) [12].

$$
\begin{gathered}
T_{\mathrm{d}}(t)=\frac{\left|T_{\max }-T_{\min }\right|}{2} \sin \left(\frac{2 \pi t}{P}-\frac{\pi}{2}\right) \\
+\frac{\left|T_{\max }-T_{\min }\right|}{2}+T_{\min },
\end{gathered}
$$

where $T_{\max }$ and $T_{\min }$ are the maximum and the minimum temperatures formed during the given day [21] and $P$ is all day-long period. The solar-air temperature for the weather data of the 21st of July and 21st of January are presented in Fig. 2 for four different cities in Turkey. Each of the cities is located in a different climatic zone of Turkey.

An explicit finite difference method is employed to obtain the numerical solution. Central differencing scheme was used for spatial term discretization, while forward difference (explicit) scheme was used for temporal 

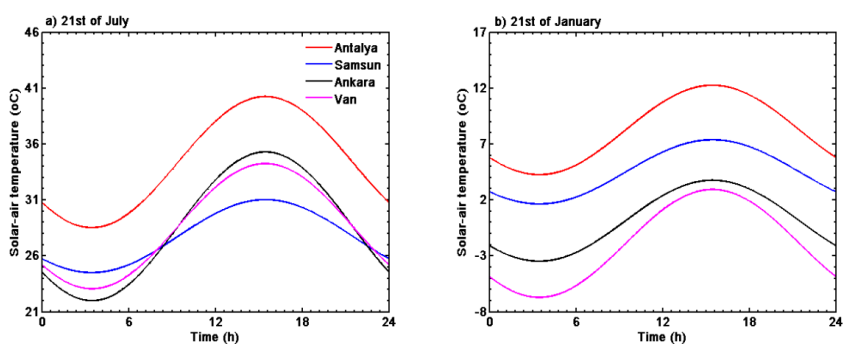

Fig. 2. Solar-air temperature profile for different cities (a) summer condition, (b) winter condition.

discretization. The steady-state solution of the problem at $t=0$ is taken as an initial condition. Time step is taken to be $15 \mathrm{~s}$. Computations are performed until the solution becomes periodic. It is observed that five day computations are enough to obtain a periodic solution.

Time lag and decrement factor are key parameters to evaluate the thermal inertia of building envelopes. Time lag indicates the required time of temperature wave from outdoor to indoor and is desired to be high, from the point of view of thermal comfort. Decrement factor is the ratio of amplitudes of inside and outside surface temperatures. TL and DF are defined by following equations [12]:

$$
\begin{aligned}
& \mathrm{TL}=\left\{\begin{array}{l}
t_{T_{\mathrm{i}}^{\max }}>t_{T_{\mathrm{o}}^{\max }} \Rightarrow t_{T_{\mathrm{i}}^{\max }}-t_{T_{\mathrm{o}}^{\max }}, \\
t_{T_{\mathrm{i}}^{\max }}<t_{T_{\mathrm{o}}^{\max }} \Rightarrow t_{T_{\mathrm{i}}^{\max }}-t_{T_{\mathrm{o}}^{\max }}+P, \\
t_{T_{\mathrm{i}}^{\max }}=t_{T_{\mathrm{o}}^{\max }} \Rightarrow P,
\end{array}\right. \\
& \mathrm{DF}=\frac{T_{\mathrm{i}}^{\max }-T_{\mathrm{i}}^{\min }}{T_{\mathrm{o}}^{\max }-T_{\mathrm{o}}^{\min }} .
\end{aligned}
$$

\section{Results and discussion}

Computations are carried out for both the wall with PCM and the wall without PCM, for performance comparison. The inside surface temperature profiles for $24 \mathrm{~h}$ for the selected cities are presented in Fig. 3 and Fig. 4 for cooling and heating conditions. As seen in Fig. 3, the inside surface temperature remains constant for a long period of the day in cities of Antalya, Ankara and Van, since for these climatic conditions, the phase change occurs and solar energy is converted into latent heat. For instance, the maximum inside temperature for Antalya decreases by about $1.5^{\circ} \mathrm{C}$ (from $22.5^{\circ} \mathrm{C}$ to $21^{\circ} \mathrm{C}$ ). Besides, it is observed that the amplitude of temperature swing of inside surface decreases significantly by integrating the PCM into the wall for these cities, particularly for Ankara where more phase change occurs.

On the other hand, such a behavior is not observed in Samsun, which indicates that the selected PCM is not appropriate for such climatic conditions. It is noted that the enhancement introduced by PCM in Samsun, in fact, is due to decreased thermal conductance.

Figure 4 shows that by incorporation of PCM into the wall, the inside surface temperature for heating conditions remains constant for a certain period of the day only for Van, due to the same reason mentioned above. The amplitude of the temperature swing decreases from $1.4^{\circ} \mathrm{C}$ to $0.4^{\circ} \mathrm{C}$ since the solar energy is absorbed in the PCM during the day and is released during the night.
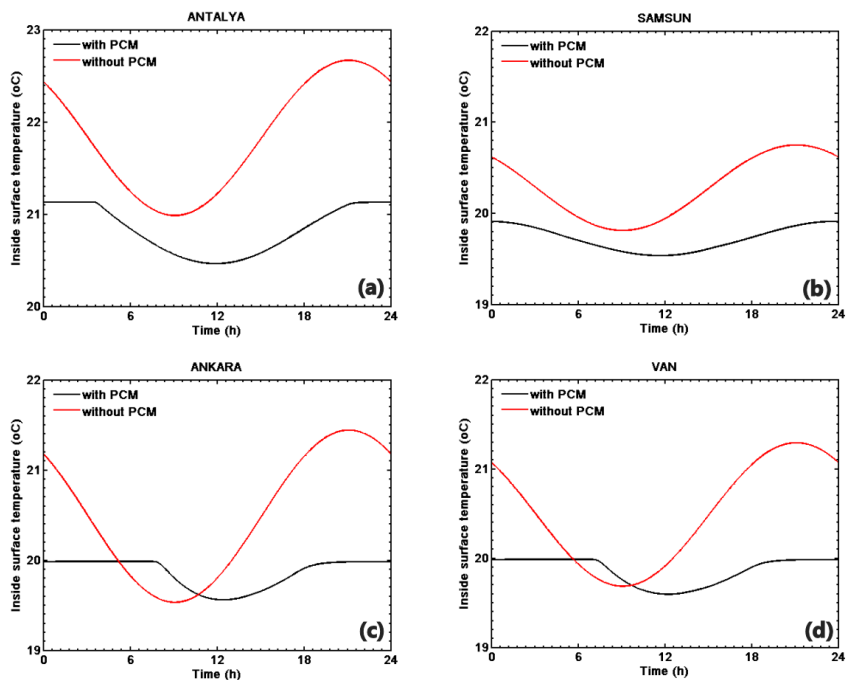

Fig. 3. Inside surface temperature profile for $24 \mathrm{~h}$ in cooling condition.
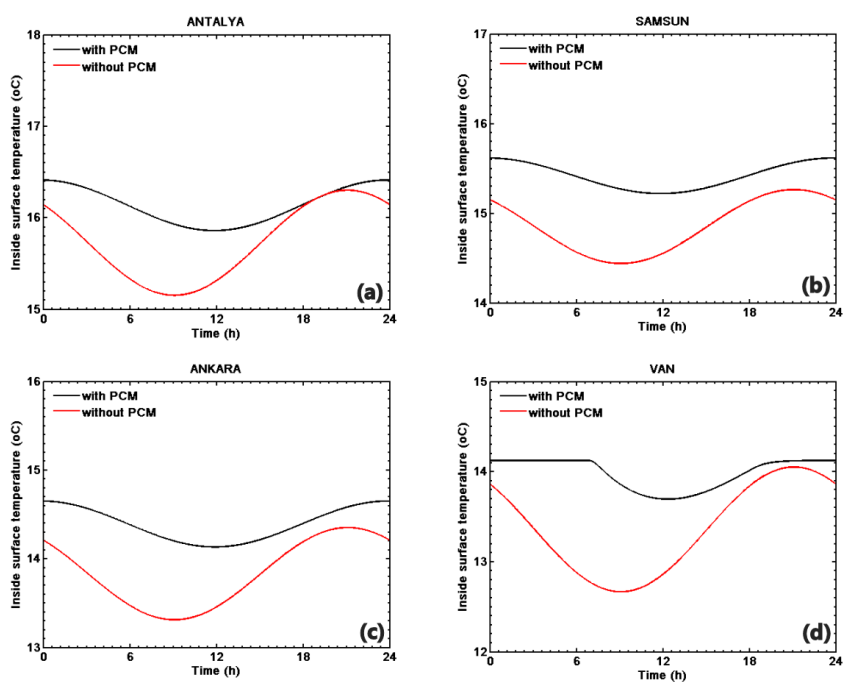

Fig. 4. Inside surface temperature profile for $24 \mathrm{~h}$ in heating condition.

TL and DF values are also calculated for the wall with PCM and without PCM in order to evaluate the thermal performance. The results are given in Table II. For the wall without PCM, TL is $5.64 \mathrm{~h}$ and DF is 0.144 , for all the cases considered. For the wall with PCM and cooling conditions, TL increases to $8.34 \mathrm{~h}, 11.98 \mathrm{~h}, 15.53 \mathrm{~h}$, and $16.11 \mathrm{~h}$ for Samsun, Antalya, Van and Ankara cities, respectively. The highest enhancement is achieved in Ankara, where the most phase change occurs.

For the heating conditions, the computational results show that TL increases from $5.64 \mathrm{~h}$ to $8.4 \mathrm{~h}$ for Samsun, Ankara and Antalya, while it increases to $15.31 \mathrm{~h}$ for Van, which is the only city where the latent heat of fu- 
sion is activated. By integrating PCM into wall, the DF values decrease substantially. The largest decrease for the cooling and heating conditions is obtained in Ankara (from 0.144 to 0.032 ) and in Van (from 0.144 to 0.045 ), respectively.

TABLE II

Time lag and decrement factor for different cities and cooling/heating conditions.

\begin{tabular}{c|c|c|c|c|c|c|c|c}
\hline \hline & \multicolumn{3}{|c|}{ Cooling condition } & \multicolumn{3}{c}{ Heating condition } \\
\hline & \multicolumn{2}{|c|}{ TL } & \multicolumn{2}{c|}{ DF } & \multicolumn{2}{c}{ TL } & \multicolumn{2}{c}{ DF } \\
\hline & with PCM & without PCM & with PCM & without PCM & with PCM & without PCM & with PCM & without PCM \\
\hline Antalya & 11.98 & 5.64 & 0.057 & 0.144 & 8.42 & 5.64 & 0.069 & 0.144 \\
Samsun & 8.34 & 5.64 & 0.058 & 0.144 & 8.40 & 5.64 & 0.069 & 0.144 \\
Ankara & 16.11 & 5.64 & 0.032 & 0.144 & 8.43 & 5.64 & 0.072 & 0.144 \\
Van & 15.53 & 5.64 & 0.035 & 0.144 & 15.31 & 5.64 & 0.045 & 0.144
\end{tabular}

The heat-saving which is defined as the difference between the required energy for the wall with PCM and the wall without PCM was calculated for the selected cities for both, heating and cooling conditions. The computational results show that the largest energy savings are attained for the cases where the difference between indoor and sol-air temperature is high and latent heat of fusion is incorporated into heat flow. For instance, the cooling energy saving is about $215 \mathrm{~W} \mathrm{~h} / \mathrm{m}^{2}$-day for Antalya while it is $121 \mathrm{Wh} / \mathrm{m}^{2}$-day for Samsun. Similarly, heating energy saving is largest in Van (about $135 \mathrm{Wh} / \mathrm{m}^{2}$ day) while it is about $88 \mathrm{Wh} / \mathrm{m}^{2}$-day in Antalya.

\section{Conclusions}

In this study, the thermal performance of two different $\mathrm{PCM}$ integrated into an external wall is investigated numerically, considering heating and cooling conditions. The impact of PCM on the time lag, decrement factor and heat-saving is examined. The calculations are performed for four different cities in Turkey, in order to explore the effect of climatic zone on the potential energy saving. A solar-air temperature, which is a function of time and solar radiation, was taken into consideration as the external boundary condition for each city.

Computed results show that the inside surface temperature increases for winter conditions and decreases for summer conditions for all the cities considered in the study, which enhances thermal comfort. Besides, it is observed that the amplitude of temperature swings decreases significantly by integrating PCM into wall. The enhancement in all the investigated parameters is more pronounced, as the difference between indoor and sol-air temperature increases.

It is concluded that by incorporating PCM into external walls, thermal comfort can be enhanced considerably and a significant amount of cooling and heating energy can be saved, particularly for the cases with large temperature difference between indoor and sol-air temperatures, however, a proper selection of the PCM, considering different climatic conditions, is of primary importance, and requires further investigation.

\section{References}

[1] A.A. Jadallah, D.Y. Mahmood, Z.A. Abdulqaedr, Acta Phys. Pol. A 128, B-461 (2015).

[2] A.A. Jadallah, D.Y. Mahmood, Z. Er, Z.A. Abdulqaedr, Acta Phys. Pol. A 130, 434 (2016).

[3] Z. Er, Acta Phys. Pol. A 128, B-477 (2015).

[4] Z. Er, Acta Phys. Pol. A 130, 72 (2016).

[5] M. Arıcı, B. Yilmaz, H. Karabay, Acta Phys. Pol. A 130, 266 (2016).

[6] M. Imal, Acta Phys. Pol. A 130, 245 (2016).

[7] B. Zalba, J.M. Marin, L.F. Cabeza, H. Mehling, Appl. Thermal Engin. 23, 251 (2003).

[8] A.K. Athienitis, C. Liu, D. Hawes, Build. Environment 32, 405 (1997).

[9] M.J. Huang, P.C. Eames, N.J. Hewitt, Solar Ener. Mater. Solar Cells 90, 1951 (2006).

[10] B.M. Diaconu, M. Cruceru, Ener. Build. 42, 1759 (2010).

[11] C.K. Halford, R.F. Boehm, Ener. Build. 39, 298 (2007).

[12] H. Asan, Build. Environment 41, 615 (2006).

[13] C. Sun, S. Shu, G. Ding, Ener. Build. 61, 1 (2013).

[14] C. Lai, S. Hokoi, Ener. Build. 73, 37 (2014).

[15] Y.A. Çengel, Heat and mass transfer, 3rd ed., McGraw-Hill, 2007, p. 849.

[16] EEC, Safety Data Sheet Rubitherm, Rubitherm, Berlin 2010, available from: www.rubitherm.eu.

[17] B. Zivkovic, I. Fujii, Solar Ener. 70, 51 (2001).

[18] R. Yumrutaş, M. Ünsal, M. Kanoğlu, Build. Environment 40, 1117 (2004).

[19] M.J. Al-Khawaja, Appl. Thermal Engin. 24, 2601 (2004).

[20] I.P. Frank, D.P. DeWitt, Fundamentals of heat and mass transfer, John Wiley \& Sons, 4th ed., 2002, p. 683.

[21] H. Bulut, O. Büyükalaca, A. Yılmaz, in: Energy and Environment Symposium (IEEES-1), Izmir, Turkey 2003, p. 499. 